OPEN ACCESS

Edited by:

Dick Tibboel,

Erasmus Medical Center, Netherlands

Reviewed by:

Kee Thai Yeo,

KK Women's and Children's

Hospital, Singapore

Tomasz Szczapa,

Poznan University of Medical

Sciences, Poland

*Correspondence:

Mo Wang

wangmo_cqmu@163.com

Specialty section: This article was submitted to Neonatology,

a section of the journa

Frontiers in Pediatrics

Received: 10 February 2021 Accepted: 07 June 2021

Published: 14 July 2021

Citation:

Hu Q, Li S-J, Chen Q-L, Chen H, Li Q and Wang M (2021) Risk Factors for

Acute Kidney Injury in Critically III

Neonates: A Systematic Review and Meta-Analysis.

Front. Pediatr. 9:666507. doi: 10.3389/fped.2021.666507

\section{Risk Factors for Acute Kidney Injury in Critically III Neonates: A Systematic Review and Meta-Analysis}

\author{
Qian $\mathrm{Hu}^{1}$, Shao-Jun $\mathrm{Li}^{2}$, Qian-Ling Chen ${ }^{3}$, Han Chen ${ }^{1}$, Qiu $\mathrm{Li}^{1}$ and Mo Wang ${ }^{1 *}$ \\ 1 Department of Nephrology, Ministry of Education Key Laboratory of Child Development and Disorders, National Clinical \\ Research Center for Child Health and Disorders, China International Science and Technology Cooperation Base of Child \\ Development and Critical Disorders, Children's Hospital of Chongqing Medical University, Chongqing, China, ${ }^{2}$ Department of \\ Emergency Department, Children's Hospital of Chongqing Medical University, Chongqing, China, ${ }^{3}$ Department of \\ Nephrology and Rheumatism, Hainan Women and Children's Medical Center, Haikou, China
}

Background and Objective: Acute kidney injury (AKI) is recognized as an independent risk factor for mortality and long-term poor prognosis in neonates. The objective of the study was to identify the risk factors for AKI in critically ill neonates to provide an important basis for follow-up research studies and early prevention.

Methods: The PubMed, Embase, Web of Science, Cochrane Library, China National Knowledge Infrastructure, WanFang Med, SinoMed, and VIP Data were searched for studies of risk factors in critically ill neonates. Studies published from the initiation of the database to November 19, 2020, were included. The quality of studies was assessed by the Newcastle-Ottawa Scale and the Agency for Healthcare Research and Quality (AHRQ) checklist. The meta-analysis was conducted with Stata 15 and drafted according to the guidelines of the Preferred Reporting Items for Systematic reviews and Meta-Analyses (PRISMA) statement.

Results: Seventeen studies (five cohort studies, ten case-control studies, and two cross-sectional studies) were included in meta-analysis, with 1,627 cases in the case group and 5,220 cases in the control group. The incidence of AKI fluctuated from 8.4 to $63.3 \%$. Fifteen risk factors were included, nine of which were significantly associated with an increased risk of $\mathrm{AKI}$ in critically ill neonates: gestational age [standardized mean difference $(\mathrm{SMD})=-0.31,95 \% \mathrm{Cl}=(-0.51,-0.12), P=0.002$ ], birthweight $[\mathrm{SMD}=-0.37,95 \% \mathrm{Cl}=(-0.67,-0.07), P=0.015], 1$-min Apgar score [SMD $=-0.61,95 \% \mathrm{Cl}=(-0.78,-0.43), P=0.000]$, 5-min Apgar score $[S M D=-0.71,95 \% \mathrm{Cl}=(-1.00,-0.41), P=0.000]$, congenital heart disease $(\mathrm{CHD})$ [odds ratio $(\mathrm{OR})=2.94,95 \% \mathrm{Cl}=(2.08,4.15), P=0.000$ ], hyperbilirubinemia $[\mathrm{OR}=2.26,95 \% \mathrm{Cl}=(1.40,3.65), P=0.001]$, necrotizing enterocolitis (NEC) $[\mathrm{OR}=6.32,95 \% \mathrm{Cl}=(2.98,13.42), P=0.000]$, sepsis $[\mathrm{OR}=2.21,95 \% \mathrm{Cl}=(1.25$, 3.89), $P=0.006$, and mechanical ventilation $[\mathrm{OR}=2.37,95 \% \mathrm{Cl}=(1.50,3.75)$, $P=0.000]$. Six of them were not significantly associated with $\mathrm{AKI}$ in critically ill neonates: age $[\mathrm{SMD}=-0.25,95 \% \mathrm{Cl}=(-0.54,0.04), P=0.095]$, male sex $[\mathrm{OR}=1.10$, $95 \% \mathrm{Cl}=(0.97,1.24), P=0.147]$, prematurity $[\mathrm{OR}=0.90,95 \% \mathrm{Cl}(0.52,1.56)$, 
$P=0.716]$, cesarean section $[\mathrm{OR}=1.52,95 \% \mathrm{Cl}(0.77,3.01), P=0.234]$, prenatal hemorrhage $[\mathrm{OR}=1.41,95 \% \mathrm{Cl}=(0.86,2.33), P=0.171]$, and vancomycin $[\mathrm{OR}=1.16$, $95 \% \mathrm{Cl}=(0.71,1.89), P=0.555]$.

Conclusions: This meta-analysis provides a preliminary exploration of risk factors in critically ill neonatal AKI, which may be useful for the prediction of AKI.

Systematic Review Registration: PROSPERO (CRD42020188032).

Keywords: neonates, acute kidney injury, risk factors, systematic review, meta-analysis

\section{INTRODUCTION}

Acute kidney injury (AKI) is characterized by an abrupt decrease in kidney function, which is significantly associated with increased mortality in neonates $(1,2)$. Due to a number of features of neonatal renal physiology including tubular immaturity and low renal blood flow, the incidence of neonatal AKI has been reported to be high (3). This increased risk for AKI makes early identification of potential risk factors for AKI in neonates important so that they can benefit from potential preventive strategies. Many studies on the risk factors of AKI in critically ill neonates were published, but there are differences between their results $(2,4-6)$. Though several studies have clarified some risk factors, there is a lack of meta-analysis evaluating these risk factors associated with the occurrence of AKI in critically ill neonates $(3,7-9)$.

This study was designed to perform a meta-analysis to identify risk factors associated with AKI in critically ill neonates. It may be helpful for the prediction of AKI in critically ill neonates.

\section{METHODS}

This meta-analysis was reported in accordance with the guidelines of the Preferred Reporting Items for Systematic Reviews and Meta-analyses (PRISMA) statement (10). The protocol for this systematic review was registered on the International Prospective Register of Systematic Reviews (PROSPERO) (registration number: CRD42020188032). This meta-analysis was conducted on the neonates admitted to the neonatal intensive care unit. Risk factors to be investigated included gestational age, birthweight, 1-min Apgar score, 5-min Apgar score, congenital heart disease (CHD), hyperbilirubinemia, necrotizing enterocolitis (NEC), mechanical ventilation, age, male sex, prematurity, Cesarean section, prenatal hemorrhage, sepsis, and vancomycin. We included cohort studies, case-control studies, and cross-sectional studies that investigated AKI as an outcome.

\section{Data Sources and Searches}

We conducted an electronic search of PubMed, Embase, Web of Science, Cochrane Library, China National Knowledge Infrastructure, WanFang Med, VIP Data, and SinoMed with the keywords including "neonates," "acute kidney injury," "risk factors," and "risk." Retrieval time was from inception to November 19, 2020. Search terms and Boolean operators included in the search strategies of PubMed and Embase are presented in online Supplementary Material 1.

\section{Study Selection}

Study selection was independently conducted by QH and SJL, with any discrepancies resolved by MW. Inclusion criteria were as follows: (1) Patients are neonates admitted to the neonatal intensive care unit; (2) the risk factors for AKI in neonates are reported; and (3) the definition of AKI is clear, such as Kidney Disease: Improving Global Outcomes (KDIGO) definition, Acute Kidney Injury Network (AKIN) definition, or arbitrary definition $(1,11,12)$. Exclusion criteria were as follows: (1) reviews, case reports, nonclinical studies, and the studies inconsistent with the purpose of evaluation; (2) full data cannot be provided; (3) repetitive reports; and (4) non-English or non-Chinese literature studies.

\section{Data Collection and Extraction}

Data were independently extracted by QH and S-JL, with any discrepancies resolved by MW. Data collected included the characteristics of the studies, the demographic characteristics of the patients, accompanying diseases, and therapeutic measures. When full data cannot be obtained from the study, we tried to contact the corresponding author to obtain all the data.

\section{Quality Assessment}

Quality assessment was independently conducted by $\mathrm{QH}$ and S-JL, with any discrepancies resolved by MW. The quality of cohort and case-control studies was assessed using the NewcastleOttawa Scale (NOS), which was widely used in the quality assessment of case-control and cohort studies $(13,14)$. The NOS conducts a comprehensive evaluation from three aspects of the study: selection, comparability, and outcome (cohort studies) or exposure (case-control studies). A study can be awarded a maximum of one point for each numbered item within the selection and exposure categories. A maximum of two points can be given for comparability. The quality of the study was assessed as follows: low quality $=0-3$; moderate quality $=4-6$; and high quality $=7-9$ (15). The quality of cross-sectional studies was assessed by the 11item checklist recommended by the Agency for Healthcare Research and Quality (AHRQ), which included the definition of information source, inclusion and exclusion criteria, time period and continuity for identifying patients, blinding of personnel, assessments for quality assurance, confounding and missing data, and response rates and completeness of patients. An item would 


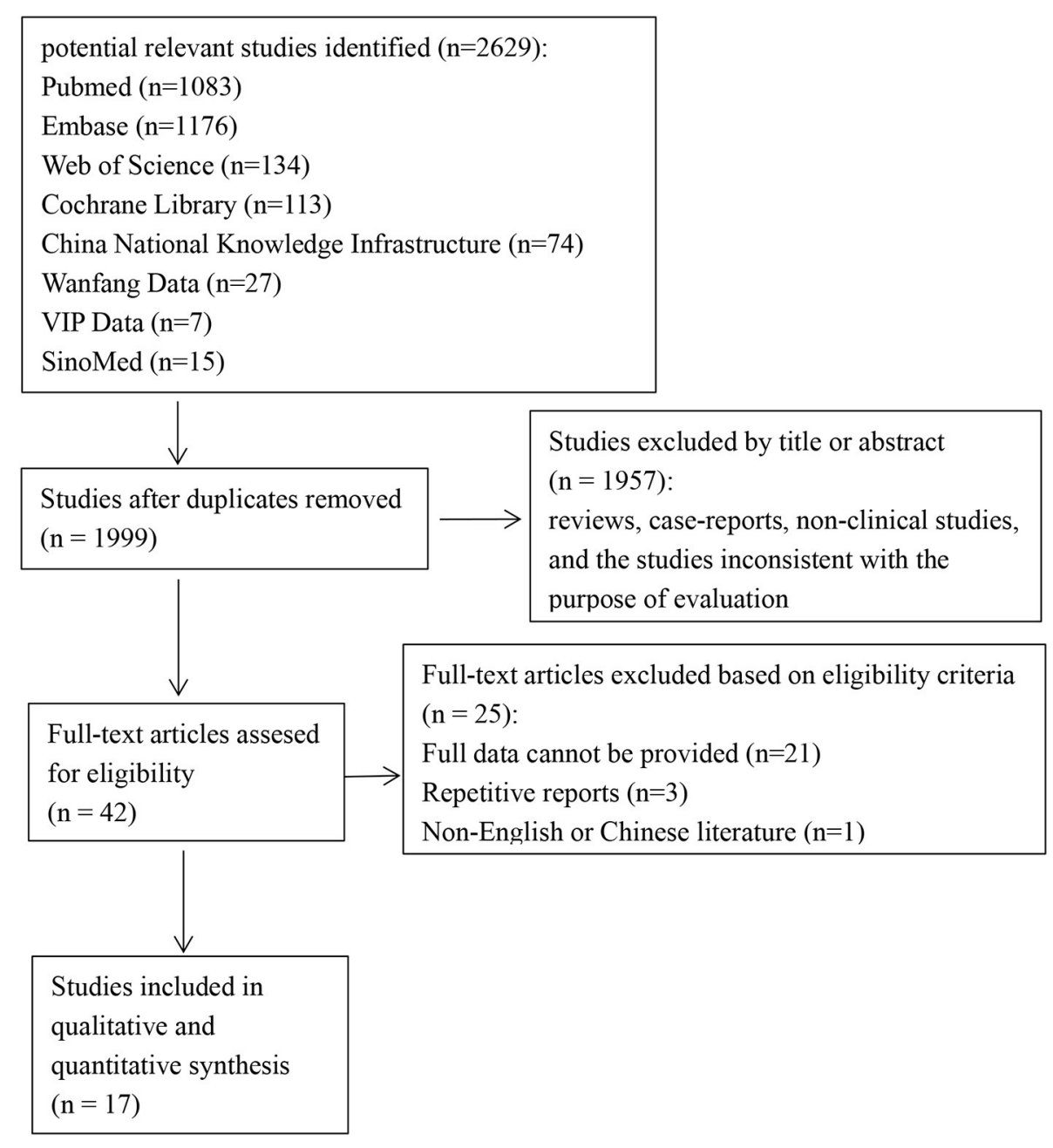

FIGURE 1 | Flowchart of the selection process for eligible studies [the preferred reporting items for systematic reviews and meta-analyses (PRISMA) 2009 flow diagram].

be scored "0" if it was answered "UNCLEAR" or "NO"; for the answer of "YES," the item would get a score of "1." Quality of the study was assessed as follows: low quality $=0-3$; moderate quality $=4-7$; and high quality $=8-11(16,17)$.

\section{Statistical Analysis}

Effect sizes have been reported in odds ratio (OR) for dichotomous data and standardized mean difference (SMD) for continuous outcomes. Raw data of continuous variables were converted into mean and standardized difference (SD) wherever possible (18). Pooled effect estimates were reported with 95\% CIs. Heterogeneity was tested using the $I^{2}$ test, with $I^{2}>50 \%$, or $p$ value $<0.1$ was considered significant. If there was significant heterogeneity, a random-effects model was used or else a fixedeffects model. Statistical significance was defined as a two-tailed $p$-value $<0.05$. Sensitivity analyses were conducted on each risk factor by removing each individual study from the overall analysis. Subgroup analyses were performed on the risk factors with significant heterogeneity, which were based on the definition of AKI (KDIGO or non-KDIGO) and research method (cohort or non-cohort study) (1). Publication bias was estimated via Egger's test, and a $p>0.05$ was considered non-significant publication bias. If there was publication bias, the non-parametric clipping was used to evaluate the impact of publication bias on the results. All statistical analyses were performed using Stata 15.0 software (19).

\section{RESULTS}

\section{Characteristics of Included Studies}

Initial screening identified 2,629 publications (Figure 1). Finally, only 17 studies satisfied our inclusion criteria and were involved in the meta-analysis $(2,4-6,12,20-31)$, including five cohort studies, ten case-control studies, and two cross-sectional studies (Table 1). Of these, nine studies employed the KDIGO definition or the KDIGO definition modified for neonates (mKDIGO), six studies employed arbitrary definitions, and two studies employed the AKIN definition. The 17 studies included in qualitative 
TABLE 1 | Basic characteristics of included studies.

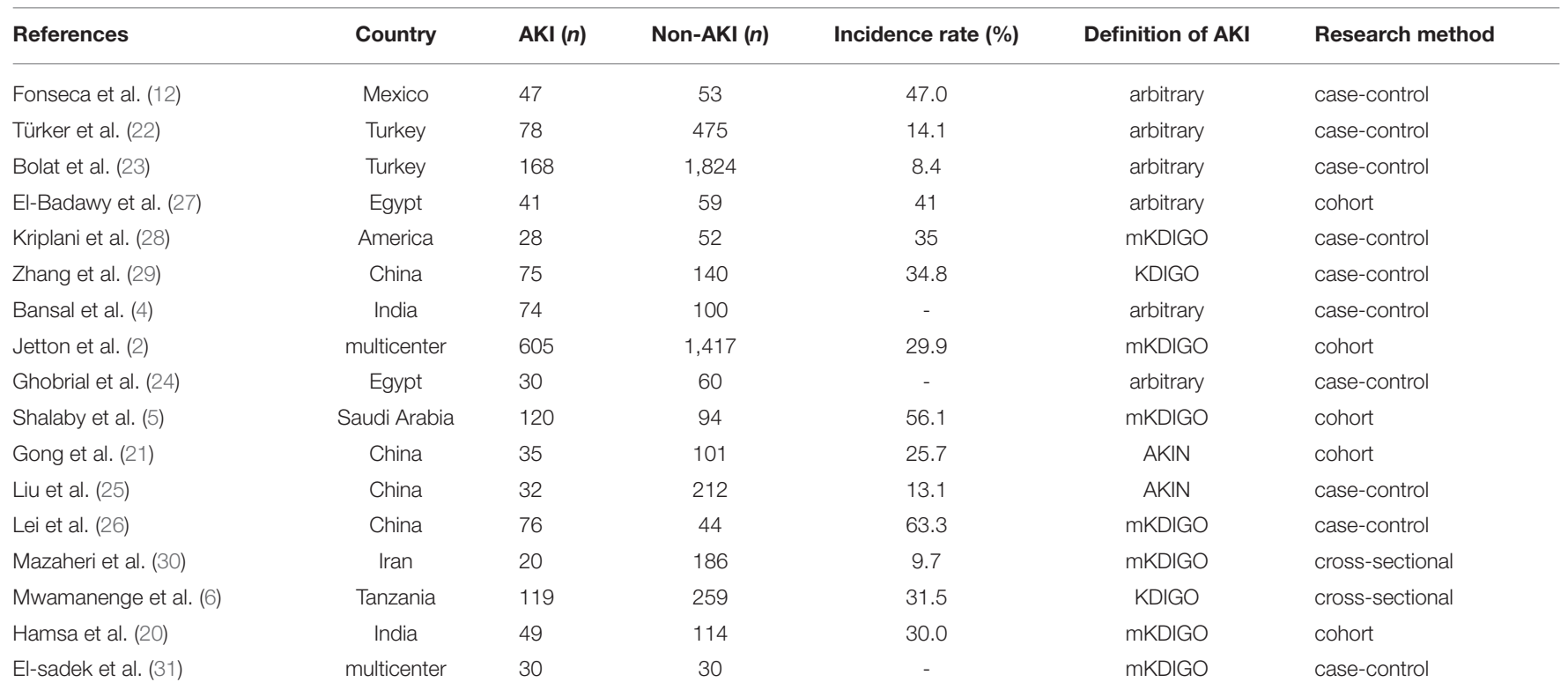

AKI, acute kidney injury; KDIGO, kidney disease: improving global outcomes definition; mKDIGO, kidney disease: improving global outcomes definition modified for neonates; AKIN, acute kidney injury network definition.

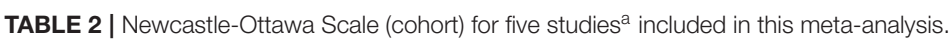

\begin{tabular}{|c|c|c|c|c|c|c|}
\hline Item & & I & II & III & IV & $\mathbf{v}$ \\
\hline $\begin{array}{l}\text { Representativeness of the } \\
\text { exposed cohort }\end{array}$ & $\begin{array}{l}\text { a) truly representative of the average__(describe) in the community\#; } \\
\text { b) somewhat representative of the average__in the community\#; } \\
\text { c) selected group of users, e.g., nurses, volunteers; } \\
\text { d) no description of the derivation of the cohort }\end{array}$ & 1 & 1 & 1 & 1 & 1 \\
\hline $\begin{array}{l}\text { Selection of the } \\
\text { nonexposed cohort }\end{array}$ & $\begin{array}{l}\text { a) drawn from the same community as the exposed cohort\#; } \\
\text { b) drawn from a different source; } \\
\text { c) no description of the derivation of the nonexposed cohort }\end{array}$ & 0 & 0 & 0 & 0 & 0 \\
\hline $\begin{array}{l}\text { Demonstration that } \\
\text { outcome of interest was not } \\
\text { present at start of study }\end{array}$ & $\begin{array}{l}\text { a) yes\#; } \\
\text { b) no }\end{array}$ & 1 & 1 & 1 & 1 & 1 \\
\hline $\begin{array}{l}\text { Was follow-up long enough } \\
\text { for outcomes to occur }\end{array}$ & $\begin{array}{l}\text { a) yes (select an adequate follow-up period for outcome of interest)\#; } \\
\text { b) no }\end{array}$ & 1 & 1 & 1 & 1 & 1 \\
\hline $\begin{array}{l}\text { Adequacy of follow-up of } \\
\text { cohorts }\end{array}$ & $\begin{array}{l}\text { a) complete follow-up - all subjects accounted for\#; } \\
\text { b) subjects lost to follow-up unlikely to introduce bias - small number lost - > _ \% } \\
\text { (select an adequate \%) follow-up, or description provided of those lost)\#; } \\
\text { c) follow-up rate <__ (select an adequate \%) and no description of those lost; } \\
\text { d) no statement }\end{array}$ & 1 & 1 & 1 & 1 & 1 \\
\hline Score & & 7 & 7 & 7 & 7 & 7 \\
\hline
\end{tabular}

a Studies: I = (2); II = (5); III = (20); $I V=(21) ; V=(27)$. \#One point. 
TABLE 3 | Newcastle-Ottawa Scale (case-control) for ten studies ${ }^{a}$ included in this meta-analysis.

\begin{tabular}{|c|c|c|c|c|c|c|c|c|c|c|c|}
\hline Item & & I & II & III & IV & $\mathbf{v}$ & VI & VII & VIII & IX & $\mathbf{x}$ \\
\hline $\begin{array}{l}\text { Was the case definition } \\
\text { adequate }\end{array}$ & $\begin{array}{l}\text { a. Yes, with independent validation^; } \\
\text { b. yes, e.g., record linkage or based on self-reports; } \\
\text { c. no description }\end{array}$ & 1 & 1 & 1 & 1 & 1 & 1 & 1 & 1 & 1 & 1 \\
\hline $\begin{array}{l}\text { Representativeness of the } \\
\text { cases }\end{array}$ & $\begin{array}{l}\text { a. Consecutive or obviously representative series of } \operatorname{cases}^{\wedge} \text {; } \\
\text { b. potential for selection biases or not stated }\end{array}$ & 1 & 1 & 1 & 1 & 1 & 1 & 1 & 1 & 1 & 1 \\
\hline Selection of controls & $\begin{array}{l}\text { a. Community controls^; } \\
\text { b. hospital controls; } \\
\text { c. no description }\end{array}$ & 0 & 0 & 0 & 0 & 0 & 0 & 0 & 0 & 0 & 0 \\
\hline Definition of controls & $\begin{array}{l}\text { a. No history of disease (endpoint) }{ }^{\wedge} \text {; } \\
\text { b. no description of source }\end{array}$ & 1 & 1 & 1 & 1 & 1 & 1 & 1 & 1 & 1 & 1 \\
\hline Comparability & $\begin{array}{l}\text { a. Study controls for } \\
\text { b. study controls for any additional factor }{ }^{\wedge} \text { (These criteria could } \\
\text { be modified to indicate specific control for a second } \\
\text { important factor.) }\end{array}$ & 0 & 1 & 1 & 0 & 1 & 1 & 1 & 1 & 1 & 2 \\
\hline Ascertainment of exposure & $\begin{array}{l}\text { a. secure records (e.g., surgical records)^; } \\
\text { b. structured interview blinded to case/control status^; } \\
\text { c. Interview not blinded to case/control status; } \\
\text { d. written self-report or medical record only; } \\
\text { e. no description }\end{array}$ & 1 & 1 & 1 & 1 & 1 & 1 & 1 & 1 & 1 & 1 \\
\hline $\begin{array}{l}\text { Same method of } \\
\text { ascertainment for cases and } \\
\text { controls }\end{array}$ & $\begin{array}{l}\text { a. yes^; } \\
\text { b. no }\end{array}$ & 1 & 1 & 1 & 1 & 1 & 1 & 1 & 1 & 1 & 1 \\
\hline Non-Response rate & $\begin{array}{l}\text { a. Same rate for both groups }{ }^{\wedge} \text {; } \\
\text { b. non-respondents described; } \\
\text { c. rate different and no designation }\end{array}$ & 1 & 1 & 1 & 1 & 1 & 1 & 1 & 1 & 1 & 1 \\
\hline Total score & & 6 & 7 & 7 & 6 & 7 & 7 & 7 & 7 & 7 & 8 \\
\hline
\end{tabular}

a Studies: I = (12); II= (22); III=(23); $I V=(4) ; V=(24) ; V I=(25) ; V I I=(26) ; V I I I=(28) ; I X=(29) ;$ and $X=(31)$.

One point.

TABLE 4 | Agency for healthcare research and quality (AHRQ) checklist (cross-sectional) for 2 studies $^{\mathrm{a}}$ included in this meta-analysis.

\begin{tabular}{|c|c|c|}
\hline Item & I & II \\
\hline 1) Define the source of information (survey, record review) & 1 & 1 \\
\hline 2) List inclusion and exclusion criteria for exposed and unexposed subjects (cases and controls) or refer to previous publications. & 1 & 1 \\
\hline 3) Indicate time period used for identifying patients. & 1 & 1 \\
\hline 4) Indicate whether or not subjects were consecutive if not population-based. & 1 & 1 \\
\hline 5) Indicate if evaluators of subjective components of study were masked to other aspects of the status of the participants. & 1 & 1 \\
\hline 6) Describe any assessments undertaken for quality assurance purposes (e.g., test/retest of primary outcome measurements). & 0 & 1 \\
\hline 7) Explain any patient exclusions from analysis. & 1 & 1 \\
\hline 8) Describe how confounding was assessed and/or controlled. & 0 & 1 \\
\hline 9) If applicable, explain how missing data were handled in the analysis. & 0 & 0 \\
\hline 10) Summarize patient response rates and completeness of data collection. & 0 & 0 \\
\hline 11) Clarify what follow-up, if any, was expected and the percentage of patients for which incomplete data or follow-up was obtained. & 0 & 1 \\
\hline Total score & 6 & 9 \\
\hline
\end{tabular}

a Studies: $I=(30) ; I=(6)$.

analysis contributed to 1,627 cases and 5,220 controls. The incidence of neonatal AKI fluctuates between 8.4 and $63.3 \%$.

\section{Quality Assessment}

Based on the NOS quality assessment and AHRQ checklist, 14 studies were classified as high quality and three studies as moderate quality (Tables $\mathbf{2 - 4}$ ). The comparability scores of the two medium-quality case-control studies are both zero.
In the cohort and case-control studies, the controls were not community based.

\section{Results of Meta-Analysis}

The analyses of risk factors are shown in Table 5. The heterogeneities of age, gestational age, birthweight, Cesarean section, 1-min Apgar score, 5-min Apgar score, prematurity, sepsis, and mechanical ventilation were significant, which, in 
TABLE 5 | Results of meta-analysis.

\begin{tabular}{|c|c|c|c|c|c|c|c|}
\hline \multirow[t]{2}{*}{ Risk factors } & \multirow[t]{2}{*}{ Number of studies } & \multirow[t]{2}{*}{ Net change $(95 \% \mathrm{Cl})$} & \multirow[t]{2}{*}{$P$} & \multicolumn{2}{|c|}{ Heterogeneity } & \multirow[t]{2}{*}{ Analysis model } & \multirow[t]{2}{*}{ Egger's test } \\
\hline & & & & $I^{2}(\%)$ & $P$ & & \\
\hline Age & 5 & $-0.25(-0.54,0.04) \#$ & 0.095 & 61.3 & 0.035 & Random & $P=0.341$ \\
\hline Male sex & 15 & $1.10(0.97,1.24)^{\wedge}$ & 0.147 & 18.2 & 0.25 & Fixed & $P=0.393$ \\
\hline Gestational age & 10 & $-0.31(-0.51,-0.12) \#$ & 0.002 & 67.8 & 0.001 & Random & $P=0.511$ \\
\hline Prematurity & 6 & $0.90(0.52,1.56)^{\wedge}$ & 0.716 & 76.4 & 0.001 & Random & $P=0.923$ \\
\hline Birthweight & 8 & $-0.37(-0.67,-0.07) \#$ & 0.015 & 84.1 & 0.000 & Random & $P=0.800$ \\
\hline Cesarean section & 3 & $1.52(0.76,3.01)^{\wedge}$ & 0.234 & 74.5 & 0.020 & Random & \\
\hline Apgar 1 & 10 & $-0.61(-0.78,-0.43) \#$ & 0.000 & 66.2 & 0.002 & Random & $P=0.020$ \\
\hline Apgar 5 & 10 & $-0.71(-1.00,-0.41) \#$ & 0.000 & 91.3 & 0.000 & Random & $P=0.140$ \\
\hline Antepartum hemorrhage & 2 & $1.41(0.86,2.33)^{\wedge}$ & 0.171 & 0.0 & 0.622 & Fixed & \\
\hline Sepsis & 11 & $2.21(1.25,3.89)^{\wedge}$ & 0.006 & 89.5 & 0.000 & Random & $P=0.003$ \\
\hline Congenital heart disease & 6 & $2.94(2.08,4.15)^{\wedge}$ & 0.000 & 0.0 & 0.558 & Fixed & $P=0.426$ \\
\hline Hyperbilirubinemia & 2 & $2.26(1.40,3.65)^{\wedge}$ & 0.001 & 0.0 & 0.726 & Fixed & \\
\hline Necrotizing enterocolitis & 4 & $6.32(2.98,13.42)^{\wedge}$ & 0.000 & 0.0 & 0.975 & Fixed & $P=0.385$ \\
\hline Mechanical ventilation & 8 & $2.37(1.50,3.75)^{\wedge}$ & 0.000 & 66.5 & 0.004 & Random & $P=0.392$ \\
\hline Vancomycin & 2 & $1.16(0.71,1.89)^{\wedge}$ & 0.555 & 0 & 0.700 & Fixed & \\
\hline
\end{tabular}

^Odds ratio (OR) and 95\% Cl; \#standardized mean difference (SMD) and 95\% Cl.

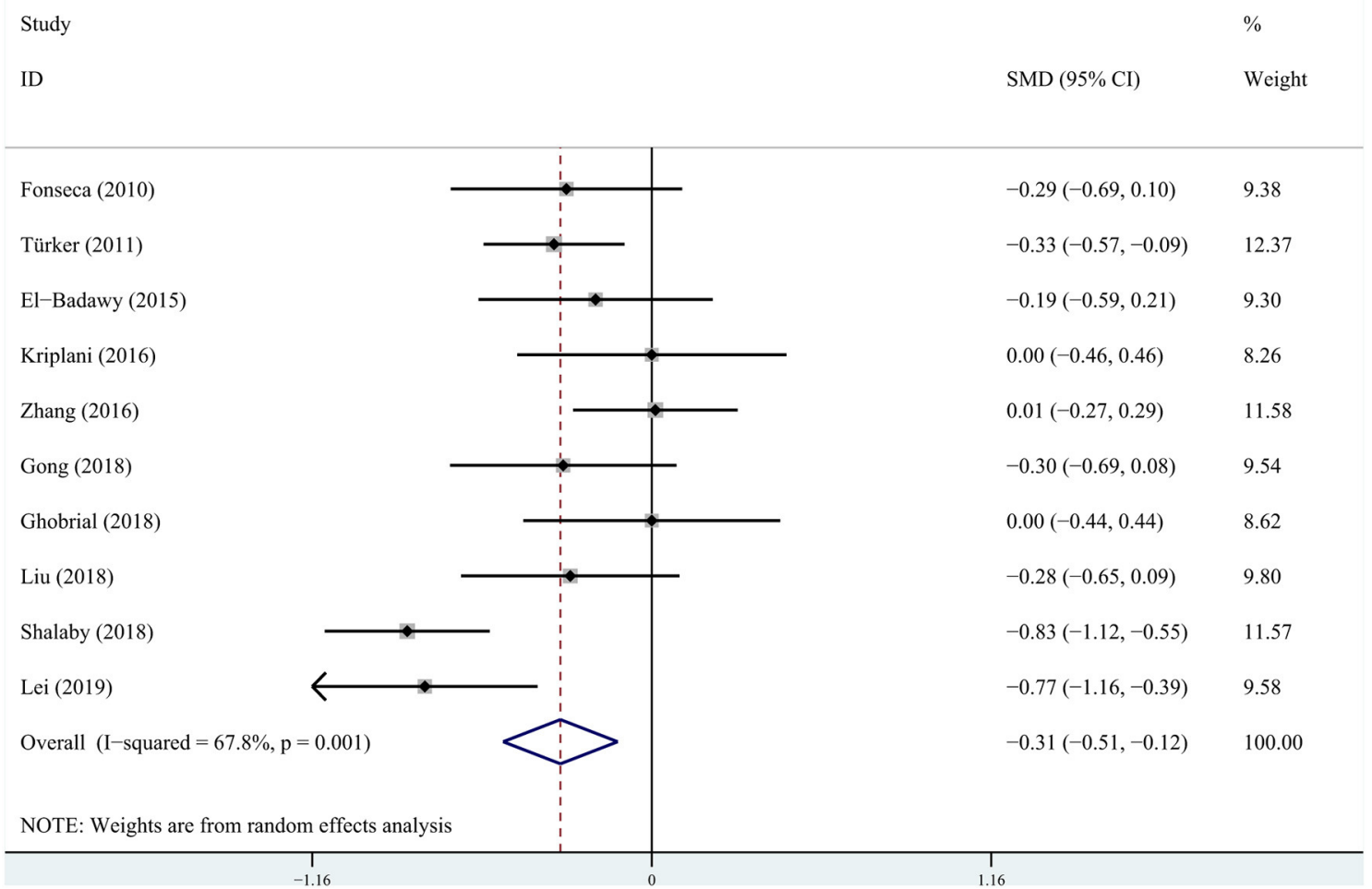

FIGURE 2 | Pooled standardized mean difference (SMD) for gestational age from random-effects meta-analysis.

turn, used the random-effects models. As for male sex, prenatal hemorrhage, $\mathrm{CHD}$, hyperbilirubinemia, NEC, and vancomycin, the heterogeneities were not significant, so fixed-effects models were used. Compared to the non-AKI group, the AKI group had lower values of gestational age $[\mathrm{SMD}=-0.31,95 \% \mathrm{CI}=$ $(-0.51,-0.12), P=0.002]$ (Figure 2), birthweight [SMD = $-0.37,95 \% \mathrm{CI}=(-0.67,-0.07), P=0.015], 1-\mathrm{min}$ Apgar score $[\mathrm{SMD}=-0.61,95 \% \mathrm{CI}=(-0.78,-0.43), P=0.000]$, and $5-\mathrm{min}$ 


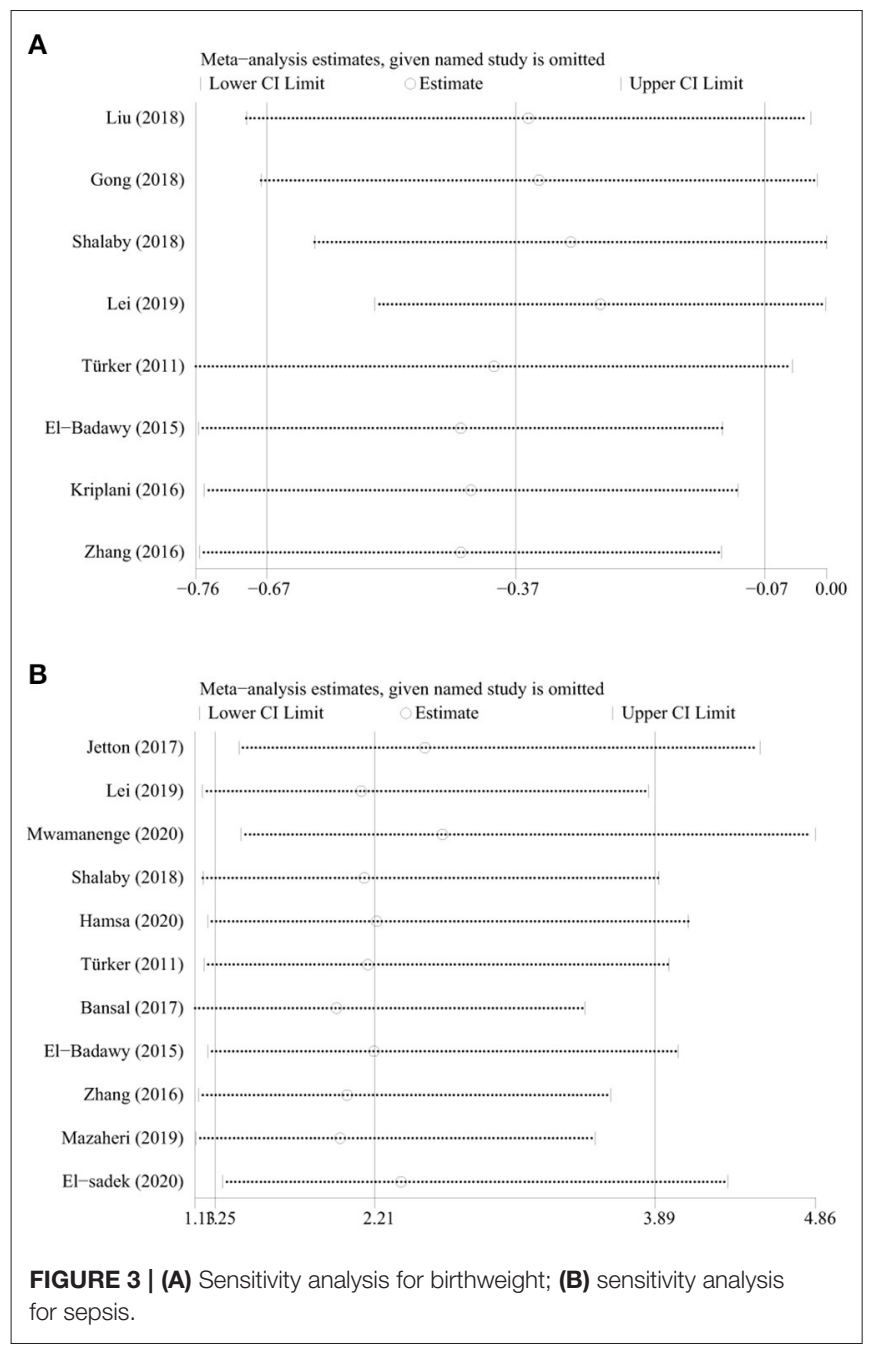

Apgar score $[\mathrm{SMD}=-0.71,95 \% \mathrm{CI}=(-1.00,-0.41), P=$ 0.000]. As compared to the non-AKI group, the AKI group had higher incidences of comorbidities such as CHD [OR $=2.94$, 95\% CI $=(2.08,4.15), P=0.000]$, hyperbilirubinemia [OR $=2.26,95 \% \mathrm{CI}=(1.40,3.65), P=0.001]$, NEC $[\mathrm{OR}=6.32$, $95 \% \mathrm{CI}=(2.98,13.42), P=0.000]$, and sepsis $[\mathrm{OR}=2.21$, $95 \% \mathrm{CI}=(1.25,3.89), \mathrm{P}=0.006]$. Compared to the nonAKI group, the AKI group was more likely to use mechanical ventilation $[\mathrm{OR}=2.37,95 \% \mathrm{CI}=(1.50,3.75), P=0.000]$. Age [SMD $=-0.25,95 \% \mathrm{CI}=(-0.54,0.04), P=0.095$ ], male sex $[\mathrm{OR}=1.10,95 \% \mathrm{CI}=(0.97,1.24), P=0.147]$, prematurity $[\mathrm{OR}=0.90,95 \% \mathrm{CI}(0.52,1.56), P=0.716]$, Cesarean section $[\mathrm{OR}=1.52,95 \% \mathrm{CI}(0.77,3.01), P=0.234]$, prenatal hemorrhage $[\mathrm{OR}=1.41,95 \% \mathrm{CI}=(0.86,2.33)$, $P=0.171]$, and vancomycin $[\mathrm{OR}=1.16,95 \% \mathrm{CI}=(0.71,1.89)$, $P=0.555]$ were not significantly associated with AKI in critically ill neonates.

\section{Sensitivity and Subgroup Analyses}

The sensitivity analyses for each risk factor showed that no individual study significantly altered the results. The results for birthweight and sepsis were shown in Figure 3. Subgroup analyses based on the research method showed that both cohort and non-cohort studies had similar results except for sepsis (Table 6). Because the studies included in the age and Cesarean section were all non-cohort studies, subgroup analyses based on the research method were not conducted. Subgroup analyses based on the definition of AKI revealed that both studies of KDIGO definition and non-KDIGO definition had similar results except for age, birthweight, and sepsis (Table 7). Because the studies included in the Cesarean section were all non-KDIGO defined, subgroup analysis based on the definition of AKI was not conducted.

\section{Publication Bias}

Assessment of publication bias using Egger's tests showed that there was no potential publication bias among the included trials in the study except for 1-min Apgar score and sepsis (Table 5). However, the results were stable after non-parametric clipping for 1-min Apgar score and sepsis.

\section{DISCUSSION}

This study revealed that early gestational age and low birthweight were significantly associated with an increased risk of AKI in critically ill neonates. This finding is consistent with the review published by Perico et al. (9). This may be attributed to the fact that the earlier the gestational age and (or) lower the birthweight, the lower the number of nephrons and their maturity $(32,33)$, which leads to an increased susceptibility toward kidney injury (34). However, we found a significant association of AKI with lower gestational age but not with preterm birth gestation $(<37$ weeks) (35). It is possible that AKI is associated with a lower gestational age cutoff and should be evaluated.

In this study, we observed that $\mathrm{CHD}$ may increase the risk of AKI in neonates by nearly three times, which may be due to the decreased renal perfusion induced by unstable hemodynamics (36). We were able to show that hyperbilirubinemia was significantly associated with an increased risk of AKI in critically ill neonates. Possible pathophysiological mechanisms are as follows: (1) Circulatory disturbance caused by liver dysfunction and portal hypertension can lead to renal hypoperfusion; (2) an afferent arterial vasoconstriction caused by inadequate effective circulatory volume and reninangiotensin-aldosterone activation; and (3) the formation of intratubular bile casts and the direct bilirubin tubular toxicity (37). In agreement with the findings of Nillsen et al., our findings indicated that the risk of AKI in neonates with NEC increased approximately by six times. This may be attributed to the fact that a significant inflammatory cascade caused by NEC can lead to microcirculatory disturbance, resulting in progressive afferent arteriolar constriction and increased pressure within the renal tubules, in turn, producing a sustained loss of filtration (38).

In agreement with the findings of van den et al. regarding AKI in critically ill neonates (39), mechanical ventilation was a risk factor. The study by Koyner et al. elaborated on the possible mechanisms, which all ultimately lead to AKI by 
TABLE 6 | Subgroup analyses based on the research method.

\begin{tabular}{|c|c|c|c|c|c|c|}
\hline \multirow[t]{2}{*}{ Risk factors } & \multirow[t]{2}{*}{ Research methods } & \multirow[t]{2}{*}{ Number of trials } & \multirow[t]{2}{*}{ Net change $(95 \% \mathrm{Cl})$} & \multirow[t]{2}{*}{$P$} & \multicolumn{2}{|c|}{ Heterogeneity } \\
\hline & & & & & $I^{2}(\%)$ & $P$ \\
\hline \multirow[t]{2}{*}{ Gestational age } & Cohort study & 3 & $-0.46(-0.89,-0.04) \#$ & 0.032 & 76.7 & 0.014 \\
\hline & Non-cohort study & 7 & $-0.24(-0.44,-0.04) \#$ & 0.017 & 55.3 & 0.037 \\
\hline \multirow[t]{2}{*}{ prematurity } & Cohort study & 2 & $0.62(0.20,1.88)^{\wedge}$ & 0.394 & 76.9 & 0.038 \\
\hline & Non-cohort study & 4 & $1.08(0.57,2.06)^{\wedge}$ & 0.818 & 77.7 & 0.004 \\
\hline \multirow[t]{2}{*}{ Birthweight } & Cohort study & 3 & $-0.43(-0.96,0.10) \#$ & 0.115 & 85.3 & 0.001 \\
\hline & Non-cohort study & 5 & $-0.34(-0.72,0.05) \#$ & 0.090 & 85.0 & 0.000 \\
\hline \multirow[t]{2}{*}{ Apgar 1} & Cohort study & 3 & $-0.64(-1.00,-0.28) \#$ & 0.001 & 83.8 & 0.002 \\
\hline & Non-cohort study & 7 & $-0.60(-0.82-0.38) \#$ & 0.000 & 48.9 & 0.068 \\
\hline \multirow[t]{2}{*}{ Apgar 5} & Cohort study & 3 & $-0.54(-0.97,-0.12) \#$ & 0.013 & 88.3 & 0.000 \\
\hline & Non-cohort study & 7 & $-0.80(-1.02,-0.58) \#$ & 0.000 & 58.10 & 0.026 \\
\hline \multirow[t]{2}{*}{ Sepsis } & Cohort study & 4 & $1.73(0.76,3.96)^{\wedge}$ & 0.191 & 88.7 & 0.000 \\
\hline & Non-cohort study & 7 & $2.58(1.09,6.13)^{\wedge}$ & 0.032 & 88.60 & 0.000 \\
\hline \multirow[t]{2}{*}{ Mechanical ventilation } & Cohort study & 3 & $2.38(1.21,4.66)^{\wedge}$ & 0.012 & 56.30 & 0.101 \\
\hline & Non-cohort study & 5 & $2.36(1.19,4.68)^{\wedge}$ & 0.014 & 74.50 & 0.003 \\
\hline
\end{tabular}

^OR and 95\% Cl; \#SMD and 95\% Cl.

Non-cohort study = case-control study or cross-sectional study.

TABLE 7 | Subgroup analyses based on the definition of AKI.

\begin{tabular}{|c|c|c|c|c|c|c|}
\hline Risk factors & Diagnostic criteria & Number of trials & Net change $(95 \% \mathrm{Cl})$ & $P$ & \multicolumn{2}{|c|}{ Heterogeneity } \\
\hline Age & Non-KDIGO & 2 & $-0.002(-0.29,0.28) \#$ & 0.987 & 0.0 & 0.896 \\
\hline \multirow[t]{2}{*}{ Gestational age } & KDIGO & 4 & $-0.41(-0.89,0.08) \#$ & 0.098 & 87.5 & 0.000 \\
\hline & Non-KDIGO & 6 & $-0.26(-0.41,-0.12) \#$ & 0.000 & 0.0 & 0.863 \\
\hline \multirow[t]{2}{*}{ Birthweight } & KDIGO & 4 & $-0.46(-1.04,0.12) \#$ & 0.122 & 91.3 & 0.000 \\
\hline & Non-KDIGO & 4 & $-0.28(-0.55,-0.01) \#$ & 0.042 & 59.8 & 0.058 \\
\hline \multirow[t]{2}{*}{ Apgar 1} & KDIGO & 6 & $-0.55(-0.77,-0.33) \#$ & 0.000 & 70.2 & 0.005 \\
\hline & Non-KDIGO & 4 & $-0.72(-0.95,-0.49) \#$ & 0.000 & 13.7 & 0.324 \\
\hline Apgar 5 & KDIGO & 5 & $-0.54(-0.86,-0.23) \#$ & 0.001 & 81.7 & 0.000 \\
\hline \multirow[t]{2}{*}{ Mechanical ventilation } & KDIGO & 2 & $2.65(1.36,5.19)^{\wedge}$ & 0.004 & 0.0 & 0.613 \\
\hline & Non-KDIGO & 6 & $2.28(1.30,3.98)^{\wedge}$ & 0.004 & 75.8 & 0.001 \\
\hline
\end{tabular}

^OR and 95\% Cl; \#SMD and 95\% Cl.

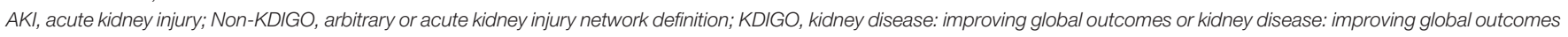
definition modified for neonates.

decreasing renal perfusion. The specific mechanisms are as follows: (1) The increase in intrathoracic pressure caused by mechanical ventilation can reduce cardiac output by compressing the mediastinal structures and pulmonary vasculature to increase the right ventricular afterload and to decrease the venous return to the heart. (2) Mechanical ventilation can alter a variety of neurohormonal systems including sympathetic outflow, the renin-angiotensin axis, nonosmotic vasopressin release, and atrial natriuretic peptide production. (3) The increased intrathoracic pressure caused by mechanical ventilation has been shown that it may directly correlate with a decrease in renal perfusion and glomerular filtration rate (40).

Constance et al. (41) in their propensity-matched cohort study, observed that combined use of vancomycin in addition to gentamicin did not increase the risk of AKI in neonates. This is similar to our result. However, some studies believe that the use of 
vancomycin can significantly increase the risk of AKI in children and adults, especially when combined with other nephrotoxic drugs and (or) diuretics $(42,43)$. Due to the inclusion of fewer studies and the lack of analysis of different doses and treatment courses of vancomycin, the result of this study needs larger sample studies to confirm.

Subgroup analysis based on the research method showed that sepsis was significantly associated with AKI in the noncohort studies while not significant in the cohort studies. So research method was one of the sources of heterogeneities. The possible explanation is that different types of studies have different strengths of evidence. According to A Manual for Evidence-based Practice (44), the exposure data of the cohort studies are collected before the outcome, so the data are reliable and the evidence of causality is good. Casecontrol studies are easily affected by confounding factors, while it is difficult for cross-sectional studies to determine the order of "exposure" and "outcome." Therefore, the strength of evidence in case-control studies is inferior to cohort studies, which in cross-sectional studies is even more inferior.

Subgroup analyses based on the definition of AKI showed that age, birthweight, and sepsis had different results between KDIGO-defined and non-KDIGO-defined studies. Meanwhile, some of the heterogeneities have declined after subgroup analyses. So the definition of AKI was one of the sources of meta-analysis. Nowadays, the diagnosis of neonatal AKI has not been unified. There are five definitions that describe the state of neonatal AKI in our meta-analysis: (1) arbitrary definition mainly based on absolute serum creatinine (SCr) $\geq 1.5 \mathrm{mg} / \mathrm{dl}$;(4, $23,24,27)$, (2) arbitrary definition based on absolute $\mathrm{SCr}$ $>1 \mathrm{mg} / \mathrm{dl}$ and $>1.3 \mathrm{mg} / \mathrm{dl}$ (for $\geq 33$ weeks and $<33$ weeks, respectively) after $48 \mathrm{~h}$ of life; (12, 22), (3) AKIN definition based on absolute $\mathrm{SCr} \geq 0.3 \mathrm{mg} / \mathrm{dl}$ or $\mathrm{SCr} \geq 1.5$ times baseline within $48 \mathrm{~h}$ or urine volume $<0.5 \mathrm{ml} / \mathrm{kg} / \mathrm{h}$ for $6 \mathrm{~h} ;(11,21,25)$, (4) KDIGO definition based on absolute $\mathrm{SCr} \geq 0.3 \mathrm{mg} / \mathrm{dl}$ within $48 \mathrm{~h}$ or SCr $\geq 1.5$ times baseline, which is known or presumed within 7 days, or urine volume $<0.5 \mathrm{ml} / \mathrm{kg} / \mathrm{h}$ for $6 \mathrm{~h} ;(1,6,29)$, and (5) modified KDIGO definition changes the baseline to previous trough value in $\operatorname{SCr}(2,5,20,26,28,30,31,45)$. As we can see, the arbitrary definitions are mainly dependent on an absolute increase in SCr for at least $1 \mathrm{mg} / \mathrm{dl}$, whose critical value is higher than that of AKIN and KDIGO. These definitions do not account for the significance in a percentage increase in $\mathrm{SCr}$ and a percentage decrease in urine output. Meanwhile, it is not difficult to find that on the basis of AKIN, KDIGO extended the time to 7 days for percentage increase in SCr. Since the baseline level of SCr changes constantly during the first week of birth, the modified KDIGO definition seems to be more suitable for the diagnosis of neonatal AKI (46). As mentioned above, the KDIGO definitions are more sensitive than AKIN and arbitrary definitions, which may be the reason why the definition of AKI became a source of heterogeneity.

Therefore, subgroup analyses indicated that the results of age, birthweight, and sepsis were not robust. It is necessary to carry out cohort studies to analyze the relationship between risk factors and different stages of AKI in critically ill neonates.

\section{LIMITATIONS}

First, this analysis was based on cross-sectional, cohort, and casecontrol studies, whose controls were not community based, so well-designed multicentric cohort studies are needed to explore the above risk factors that are relied on as causal factors associated with AKI in critically ill neonates. Second, some of the risk factors studied, such as antepartum hemorrhage, hyperbilirubinemia, and vancomycin, were assessed in only two publications, which prevented more robust meta-analyses of these factors. Third, birth asphyxia was not included in this analysis for only one study that provided corresponding data (4). Fourth, among the 17 included studies, only 10 studies excluded congenital anomalies of the kidney and urinary tract $(2,5,6,22,24,26,28-31)$, and 2 studies excluded lethal chromosomal anomaly $(2,5)$, which may bring some bias to the results. Finally, the studies included have a large time span, and different clinical factors, such as different treatment methods, may bring some bias.

\section{CONCLUSIONS}

In this study, we found the incidence of AKI fluctuates from 8.4 to $63.3 \%$. Gestational age, birthweight, 1-min Apgar score, 5-min Apgar score, CHD, hyperbilirubinemia, NEC, sepsis, and mechanical ventilation were risk factors for AKI in critically ill neonates. Well-designed studies with a considerable number of critically ill neonates are necessary to determine the possible link between these nine risk factors and AKI.

\section{DATA AVAILABILITY STATEMENT}

The original contributions presented in the study are included in the article/Supplementary Material, further inquiries can be directed to the corresponding author/s.

\section{AUTHOR CONTRIBUTIONS}

$\mathrm{QH}$, S-JL, and MW contributed to the study concept and design, article selection and quality assessment, data analysis and interpretation, and manuscript writing. Q-LC, HC, and QL contributed to the study concept and design, and manuscript writing. All authors contributed to the article and approved the submitted version.

\section{FUNDING}

The study were financially supported by the Science and Technology Program Funding Project of Yuzhong District, Chongqing (Grant number: 2017045) and National Clinical Research Center for Child Health and Disorders Funding Project (Grant number: NCRCCHD-2020-GP-0X).

\section{SUPPLEMENTARY MATERIAL}

The Supplementary Material for this article can be found online at: https://www.frontiersin.org/articles/10.3389/fped. 2021.666507/full\#supplementary-material 


\section{REFERENCES}

1. Kellum JA and Lameire N. Diagnosis, evaluation, and management of acute kidney injury: a KDIGO summary (Part 1). Crit Care. (2013) 17:204. doi: 10.1186/cc11454

2. Jetton JG, Boohaker LJ, Sethi SK, Wazir S, Rohatgi S, Soranno DE, et al. Incidence and outcomes of neonatal acute kidney injury (AWAKEN): a multicentre, multinational, observational cohort study. Lancet Child Adolesc Health. (2017) 1:184-94. doi: 10.1016/S2352-4642(17)30069-X

3. Selewski DT, Charlton JR, Jetton JG, Guillet R, Mhanna MJ, Askenazi DJ, et al. Neonatal acute kidney injury. Pediatrics. (2015) 136:e463e73. doi: 10.1542/peds.2014-3819

4. Bansal SC, Nimbalkar AS, Kungwani AR, Patel DV, Sethi AR, Nimbalkar SM. Clinical profile and outcome of newborns with acute kidney injury in a level 3 neonatal unit in Western India. J Clin Diagn Res. (2017) 11:SC014. doi: 10.7860/JCDR/2017/23398.9327

5. Shalaby MA, Sawan ZA, Nawawi E, Alsaedi S, Al-Wassia H, Kari JA. Incidence, risk factors, and outcome of neonatal acute kidney injury: a prospective cohort study. Pediatr Nephrol. (2018) 33:161724. doi: 10.1007/s00467-018-3966-7

6. Mwamanenge NA, Assenga E, Furia FF. Acute kidney injury among critically ill neonates in a tertiary hospital in Tanzania; Prevalence, risk factors and outcome. PLoS ONE. (2020) 15:e0229074 doi: 10.1371/journal.pone.0229074

7. Hanna MH, Askenazi DJ, Selewski DT. Drug-induced acute kidney injury in neonates. J Matern Fetal Neonatal Med. (2016) 28:18087. doi: 10.1097/MOP.0000000000000311

8. Murphy HJ, Thomas B, Van Wyk B, Tierney SB, Selewski DT, Jetton JG. Nephrotoxic medications and acute kidney injury risk factors in the neonatal intensive care unit: clinical challenges for neonatologists and nephrologists. Pediatr Nephrol. (2019) 35:2077-88. doi: 10.1007/s00467-019-0 4350-3

9. Perico N, Askenazi D, Cortinovis M, Remuzzi G. Maternal and environmental risk factors for neonatal AKI and its long-term consequences. Nat Rev Nephrol. (2018) 14:688-703. doi: 10.1038/s41581-018-0054-y

10. Moher D, Liberati A, Tetzlaff J, Altman DG. Preferred reporting items for systematic reviews and meta-analyses: the PRISMA statement. Int J Surg. (2010) 8:336-41. doi: 10.1016/j.ijsu.2010.02.007

11. Mehta RL, Kellum JA, Shah SV, Molitoris BA, Ronco C, Warnock DG. Acute Kidney Injury Network: report of an initiative to improve outcomes in acute kidney injury. Critical Care. (2007) 11:R31. doi: 10.1186/cc5713

12. Fonseca LDP, Pereyra MA, Mandeville P, Escalante FJ. Risk factors associated with the development of acute kidney injury in critically ill newborn infants. Pediatr Nephrol. (2010) 25:1973. doi: 10.1007/s00467-010-1577-Z

13. Mao DH, Miao JK, Zou X, Chen N, Yu LC, Lai X, et al. Risk factors in predicting prognosis of neonatal bacterial meningitis-a systematic review. Front Neurol. (2018) 9:929. doi: 10.3389/fneur.2018.00929

14. Baldacci S, Santoro M, Coi A, Mezzasalma L, Bianchi F, Pierini A. Lifestyle and sociodemographic risk factors for gastroschisis: a systematic review and meta-analysis. Arch Dis Chil. (2020) 105:756-64. doi: 10.1136/archdischild-2019-318412

15. Wells GA, Shea B, O'Connell D, Peterson J, Welch V, Losos M, et al. The Newcastle-Ottawa Scale (NOS) for assessing the quality if nonrandomized studies in meta-analyses. Available online at: http://www.ohri.ca/programs/ clinical_epidemiology/oxford.htm (accessed April 13, 2021).

16. Rostom A, Dubé C, Cranney A, Saloojee N, Sy R, Garritty C, et al. Celiac Disease. Evidence Reports/Technology Assessments, No. 104. Appendix D. Quality Assessment Forms. Rockville MD: Agency for Healthcare Research and Quality (US) (2004).

17. Hu J, Dong Y, Chen X, Liu Y, Ma D, Liu X, et al. Prevalence of suicide attempts among Chinese adolescents: a meta-analysis of cross-sectional studies. Compr Psychiatry. (2015) 61:78-89. doi: 10.1016/j.comppsych.2015.05.001

18. Wan X, Wang W, Liu J, Tong T. Estimating the sample mean and standard deviation from the sample size, median, range and/or interquartile range. BMC Med Res Methodol. (2014) 14:135. doi: 10.1186/1471-2288-14-135

19. The suggested citation for the Stata 15 software is StataCorp. 2017. Stata Statistical Software: Release 15. College Station, TX: StataCorp LLC (2017).

20. Hamsa V, Nesargi SV, Prashantha YN, John MA, Iyengar A. Acute kidney injury in sick neonates: a comparative study of diagnostic criteria, assessment of risk factors and outcomes. J Matern Fetal Neonatal Med. (2020) 22:17. doi: 10.1080/14767058.2020.1742319

21. Gong HR, Cao Y, Xu H. Early diagnosis of neonatal acute kidney injury in NICU. Chin J Pract Pediatr. (2018) 33:122-26. doi: 10.19538/j.ek201802061

22. Türker G, Özsoy G, Günlemez A, Gökalp AS, Arisoy AE, Bircan Z. Acute renal failure SNAPPE and mortality. Pediatr Int. (2011) 53:48388. doi: 10.1111/j.1442-200X.2011.03377.x

23. Bolat F, Comert S, Bolat G, Kucuk O, Can E, Bulbul A, et al. Acute kidney injury in a single neonatal intensive care unit in Turkey. World J Pediatr. (2013) 9:323-29. doi: 10.1007/s12519-012-0371-3

24. Ghobrial EE, Elhouchi SZ, Eltatawy SS, Beshara LO. Risk factors associated with acute kidney injury in newborns. Saudi J Kidney Dis Transpl. (2018) 29:81-7. doi: 10.4103/1319-2442.225179

25. Liu YL, Yue XZ, Zhao SM, Wu HM, Wei B, Wei KL. Associated factors of acute kidney injury in critically ill neonates. Chin Pediatr Emerg Med. (2018) 25:462-66. doi: 10.3760/cma.j.issn.1673-4912.2018.06.015

26. Lei BY, Su HB, Gan JJ and Liang C. Incidence, risk factors and outcome of acute kidney injury in neonates. Mod Med J. (2019) 47:1058-62. doi: 10.3969/j.issn.1671-7562.2019.09.002

27. El-Badawy AA, Makar S, Abdel-Razek ARA, Abd Elaziz D. Incidence and Risk factors of acute kidney injury among the critically ill neonates. Saudi J Kidney Dis Transpl. (2015) 26:549-55. doi: 10.4103/1319-2442.1 57362

28. Kriplani DS, Sethna CB, Leisman DE, Schneider JB. Acute kidney injury in neonates in the PICU. Pediatr Crit Care Med. (2016) 17:e159e64. doi: 10.1097/PCC.0000000000000668

29. Zhang Y, Xie J, Liu YQ, Zhao RX, Hu T, Zhao FH, et al. Relevant factor analysis of pathogenesis and prognosis of neonatal acute. Prog Mod Biomed. (2016) 16:24. doi: 10.13241/j.cnki.pmb.2016.24.026

30. Mazaheri M, Rambod M. Risk factors analysis for acute kidney injury in the newborn infants, predictive strategies. Iran J Kidney Dis. (2019) 13:310-15.

31. El-sadek AE, El-Gamasy MA, Behiry EG, Torky AA, Fathy MA. Plasma cystatin $C$ vs. renal resistive index as early predictors of acute kidney injury in critically ill neonates. JPediatr Urol. (2020) 16:206.e1-206.e8. doi: 10.1016/j.jpurol.2019. 12.001

32. Rodríguez MM, Gómez AH, Abitbol CL, Chandar JJ, Duara S, Zilleruelo GE. Histomorphometric analysis of postnatal glomerulogenesis in extremely preterm infants. Pediatr Dev Pathol. (2004) 7:17-25. doi: 10.1007/s10024-003-3029-2

33. Kandasamy Y, Smith R, Wright IM, Lumbers ER. Relationships between glomerular filtration rate and kidney volume in low-birth-weight neonates. J Nephrol. (2013) 26:894-8. doi: 10.5301/jn.5000220

34. Wang X, Johnson AC, Williams JM, White T, Chade AR, Zhang J, et al. Nephron deficiency and predisposition to renal injury in a novel one-kidney genetic model. J Am Soc Nephrol. (2015) 26:163446. doi: 10.1681/ASN.2014040328

35. Dubois M, Legouhy A, Corouge I, Commowick O, Morel B, Pladys $\mathrm{P}$, et al. Multiparametric analysis of cerebral development in preterm infants using magnetic resonance imaging. Front Neurosci. (2021) 15:658002. doi: 10.3389/fnins.2021.658002

36. O’Neal JB, Shaw AD, Billings FTt. Acute kidney injury following cardiac surgery: current understanding and future directions. Crit Care. (2016) 20:187. doi: 10.1186/s13054-016-1352-Z

37. Sens F, Bacchetta J, Rabeyrin M, Juillard L. Efficacy of extracorporeal albumin dialysis for acute kidney injury due to cholestatic jaundice nephrotoxicity. BMJ Case Rep. (2016) 2016:bcr2015213257. doi: 10.1136/bcr-2015213257

38. Nillsen A and Kent AL. Sepsis and neonatal acute kidney injury. $J$ Pediatr Infect Dis. (2016) 11:55-64. doi: 10.1055/s-0036-15 97299

39. van den Akker JP, Egal M, Groeneveld AB. Invasive mechanical ventilation as a risk factor for acute kidney injury in the critically ill: a systematic review and meta-analysis. Crit Care. (2013) 17:R98. doi: 10.1186/cc12743

40. Koyner JL, Murray PT. Mechanical ventilation and the kidney. Blood Purif. (2010) 29:52-68. doi: 10.1159/000259585

41. Constance JE, Balch AH, Stockmann C, LiNon-AKIs MW, Korgenski EK, Roberts JK, et al. A propensity-matched cohort study of 
vancomycin-associated nephrotoxicity in neonates. Arch Dis Child Fetal Neonatal Ed. (2016) 101:F236-43. doi: 10.1136/archdischild-2015-308459

42. McKamy S, Hernandez E, Jahng M, Moriwaki T, Deveikis A, Le J. Incidence and risk factors influencing the development of vancomycin nephrotoxicity in children. J Pediatr. (2011) 158:422-6. doi: 10.1016/j.jpeds.2010.08.019

43. Carreno J, Smiraglia T, Hunter C, Tobin E, Lomaestro B. Comparative incidence and excess risk of acute kidney injury in hospitalised patients receiving vancomycin and piperacillin/tazobactam in combination or as monotherapy. Int J Antimicrob Agents. (2018) 52:643-50. doi: 10.1016/j.ijantimicag.2018.08.001

44. Guyatt G, Rennie D, Meade MO, Cook DJ. Users' Guides to the Medical Literature: Essentials of Evidence-Based Clinical Practice. 3rd ed. New York, NY: McGraw Hill Education \& The JAMA Network (2015)

45. Jetton JG, Askenazi DJ. Update on acute kidney injury in the neonate. Curr Opin Pediatr. (2012) 24:191-6. doi: 10.1097/MOP.0b013e32834f62d5
46. Gallini F, Maggio L, Romagnoli C, Marrocco G, Tortorolo G. Progression of renal function in preterm neonates with gestational age $<$ or $=32$ weeks. Pediatr Nephrol. (2000) 15:119-24. doi: 10.1007/s004670000356

Conflict of Interest: The authors declare that the research was conducted in the absence of any commercial or financial relationships that could be construed as a potential conflict of interest.

Copyright (C) $2021 \mathrm{Hu}, \mathrm{Li}$, Chen, Chen, Li and Wang. This is an open-access article distributed under the terms of the Creative Commons Attribution License (CC BY).

The use, distribution or reproduction in other forums is permitted, provided the original author(s) and the copyright owner(s) are credited and that the original publication in this journal is cited, in accordance with accepted academic practice. No use, distribution or reproduction is permitted which does not comply with these terms. 